\title{
Initial and Long-Term Outcomes of Complex Bifurcation Aneurysms Treated by Y-Stent-Assisted Coiling with Low- Profile Braided Stents
}

\author{
(DK. Aydin, ${ }^{D}$ S. Men, (D) M. Barburoglu, DS. Sencer, and DS. Akpek
}

\begin{abstract}
BACKGROUND AND PURPOSE: Coiling complex intracranial bifurcation aneurysms often necessitates the implantation of double stents in various configurations, such as Y-stent placement. Low-profile braided stents have been introduced recently to facilitate the endovascular treatment of wide-neck aneurysms. We aimed to investigate the feasibility, safety, efficacy, and durability of Y-stent-assisted coiling with double low-profile braided stents for the treatment of complex bifurcation aneurysms.
\end{abstract}

MATERIALS AND METHODS: A retrospective review was performed to identify patients who were treated using Y-stent-assisted coiling with low-profile braided stents. Technical success was assessed, as were initial and follow-up clinical and angiographic outcomes. Periprocedural and delayed complications were reviewed. Preprocedural and follow-up clinical statuses were assessed using the modified Rankin Scale.

RESULTS: Forty patients with 40 intracranial aneurysms were included in the study. Y-stent placement was successfully performed in all cases. Immediate postprocedural digital subtraction angiography images revealed total aneurysm occlusion in $72.5 \%$ of cases. The mean angiographic follow-up time was 24.8 months. The last follow-up angiograms showed complete occlusion in $85 \%$ of patients. During follow-up, only 1 patient showed an increase in the filling status of the aneurysm and that patient did not require retreatment. There was no mortality in this study. The overall procedure-related complication rate, including asymptomatic complications, was $17.5 \%$. A permanent morbidity developed in 1 patient $(2.5 \%)$.

CONCLUSIONS: The long-term angiographic and clinical outcomes of this retrospective study demonstrate that $Y$-stent-assisted coiling using low-profile braided stents is an effective, relatively safe, and durable endovascular treatment for wide-neck and complex bifurcation aneurysms.

$\mathbf{S}$ tent-assisted coiling is an endovascular technique that has been described as a method to treat wide-neck intracranial aneurysms. Implantation of a self-expandable stent creates a mechanical scaffold in the parent artery to prevent coil protrusion during the endovascular treatment of wide-neck aneurysms. Several studies have demonstrated the safety, efficacy, and durability of stent-assisted coiling procedures for the treatment of wideneck aneurysms. ${ }^{1-3}$ The availability of self-expandable intracranial stents enabled the endovascular treatment of wide-neck

Received August 17, 2018; accepted after revision September 18.

From the Department of Radiology (K.A., S.S.), Neuroradiology Division, Istanbul Faculty of Medicine, Istanbul University, Istanbul, Turkey; Department of Radiology (K.A., M.B.), Koç University Medical School, Istanbul, Turkey; Department of Radiology (S.M.), Dokuz Eylul University, Izmir, Turkey; and Department of Radiology (S.A.), VKV American Hospital, Istanbul, Turkey.

Please address correspondence to Kubilay Aydin, MD, Department of Radiology, Neuroradiology Division, Istanbul Faculty of Medicine, Istanbul University, Istanbul, Turkey; e-mail: dr.aydink@gmail.com

http://dx.doi.org/10.3174/ajnr.A5869 aneurysms that could not be previously coiled. However, endovascular treatment of complex bifurcation aneurysms incorporating $>1$ daughter branch remains a challenge for neurointerventionalists. Implantation of a single stent may not be sufficient to protect both daughter branches that originate from the neck of a bifurcation aneurysm. Therefore, endovascular treatment of complex bifurcation aneurysms involving multiple daughter branches often necessitates implantation of double stents in various configurations, such as X-, T-, and Y-stent placement. ${ }^{4-8}$ Among these dual stent-placement techniques, Y-stent-assisted coiling was described by Chow et $\mathrm{al}^{9}$ in 2004 and has been widely used to treat complex bifurcation aneurysms. ${ }^{10}$ Several studies have shown the safety and efficacy of the Y-stent-assisted coiling procedure using various combinations of open-cell and closedcell laser-cut stents. However, data regarding the angiographic and clinical outcomes of Y-stent-assisted coiling with 2 braided stents are very limited in the literature. ${ }^{11-15}$

Low-profile braided stents have been introduced recently to assist in the endovascular treatment of wide-neck intracranial an- 
eurysms located in small arteries. ${ }^{16-18}$ These stents can be delivered through microcatheters with an internal diameter of 0.0165 inches; this small diameter facilitates navigation in small vessels and improves the safety of stent placement during the treatment of distal wide-neck aneurysms. Low-profile braided stents have several advantages over laser-cut stents. The former type has a sliding-strut design that allows improved wall apposition and scaffolding compared with what laser-cut stents can achieve. However, because the metal density of low-profile braided stents is higher and the pore sizes are smaller than those of laser-cut stents, there are concerns about the feasibility and safety of performing a Y-stent placement procedure with 2 low-profile braided stents.

In this retrospective study, we aimed to investigate the feasibility, safety, and efficacy of the Y-stent-assisted coiling procedure with double low-profile braided stents for the treatment of complex bifurcation aneurysms. In this study, we used only LEO Baby stents (Balt Extrusion, Montmorency, France), and we also assessed the long-term angiographic and clinical outcomes of patients with complex bifurcation aneurysms treated with Y-stentassisted coiling using only low-profile braided stents.

\section{MATERIALS AND METHODS Patient Population}

After approval was obtained from the institutional review board of Istanbul Faculty of Medicine, we performed a retrospective review of the interventional data base records. Patients with an intracranial bifurcation aneurysm who were treated with the Ystent-assisted coiling technique using only low-profile braided stents between July 2012 and January 2018 were identified. In each case with a diagnosis of intracranial aneurysm, the decisions regarding the indication for treatment and the most appropriate method of treatment were made by multidisciplinary neurovascular teams of experienced interventional neuroradiologists and vascular neurosurgeons, who considered multiple factors such as the morphology of the aneurysm sac, the morphologic relationships between the aneurysm neck and daughter branches, the anatomy of the target and parent arteries, the medical condition of the patient, and any contraindications for antiplatelet therapy. A Y-stent-assisted coiling procedure was performed to treat patients with wide-neck and complex bifurcation aneurysms. Wideneck aneurysms were defined as aneurysms with a dome-to-neck ratio of $<2$ or a neck diameter of $>4 \mathrm{~mm}$. Complex bifurcation aneurysms were defined as wide-neck aneurysms incorporating $>1$ daughter vessel of an intracranial bifurcation. The patients' medical records and radiologic images were collected. Three interventional neuroradiologists (K.A., S.M., S.A.) evaluated the patients' procedure reports, medical charts, and radiologic images. The patients' demographics, presenting symptoms, location and size of aneurysms, medical history related to intracranial aneurysms, stent deployment success, technical and clinical complications, and degree of aneurysm occlusion were recorded.

\section{Endovascular Procedure}

Antiplatelet therapy including $75 \mathrm{mg}$ of clopidogrel and $300 \mathrm{mg}$ of aspirin daily was started at least 5 days before the endovascular procedure in every patient. Platelet aggregation inhibition was

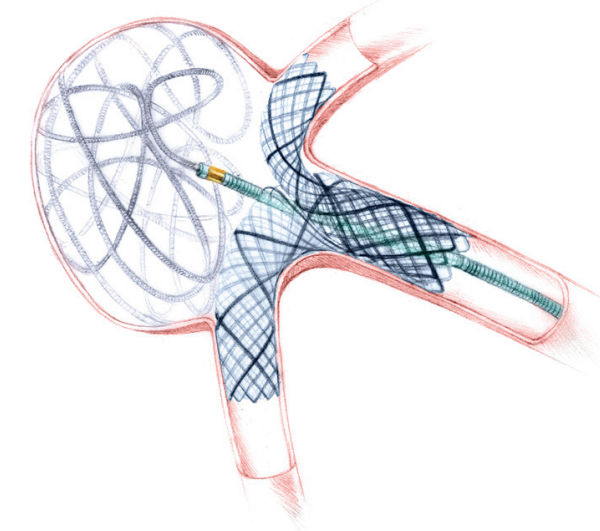

FIG 1. An illustration demonstrating the Y-stent-assisted coiling procedure using 2 braided stents.

tested before the procedure (Multiplate Analyzer, Roche Diagnostics, Mannheim, Germany; or VerifyNow P2Y12 assay, Accumetrics, San Diego, California) to confirm a good response to clopidogrel. Patients who responded inadequately to clopidogrel were switched to prasugrel $(10 \mathrm{mg} /$ day $)$ or ticagrelor $(2 \times 90$ $\mathrm{mg} /$ day).

Every endovascular procedure was performed using a femoral approach with the patient under general anesthesia. Intraprocedural anticoagulation was initiated immediately after the insertion of a femoral introducer sheath with a bolus dose of $5000 \mathrm{IU}$, followed by a heparin infusion to maintain an activated clotting time between 250 and 300 seconds during the procedure. A $6 \mathrm{~F}$ guiding sheath (Neuron Max 088; Penumbra, Alameda, California) or an 8F guiding catheter (Envoy; Codman \& Shurtleff, Raynham, Massachusetts) was placed into the target artery. Two milligrams of nimodipine (Nimotop) diluted with $0.9 \% \mathrm{NaCl}$ to a concentration of $0.05 \mathrm{mg} / \mathrm{mL}$ was infused through a guiding catheter for 15 minutes $(10 \mathrm{~mL} / \mathrm{min})$ to prevent the development of vasospasm caused by guidewire or catheter maneuvers. A microcatheter with an internal diameter of 0.0165 inches (Echelon 10 microcatheter, Covidien, Irvine, California; or Vasco 10, Balt Extrusion) for the delivery of the first stent was placed into the daughter branch arising at a more acute angle from the aneurysm neck. Another microcatheter for coiling (Echelon 10; or Headway 17, MicroVention, Tustin, California) was jailed in the sac of the aneurysm before the stents were deployed. A LEO Baby stent was deployed into the first daughter branch, extending proximal to the main parent artery. Then, the second daughter branch was catheterized with a stent-delivery microcatheter by passing through the interstices of the initial stent. The second LEO Baby stent was deployed into the second daughter branch extending proximal to the main parent artery by passing through the interstices of the initial stent, creating a Y-stent configuration. The second stent was deployed by pushing the delivery catheter together with the deployment wire to ensure good expansion of the stent in the interstices of the initial stent. After the deployment of both stents, the coiling procedure was initiated with various bare platinum coils (Target Detachable Coils, Stryker Neurovascular, Kalamazoo, Michigan; MicroPlex/Cosmos/HyperSoft 3D, MicroVention; Axium, Covidien) (Fig 1).

The coiling procedure was considered complete when com- 
plete occlusion of the aneurysm sac was achieved or no further coils could be safely deployed (Fig 1). At the end of the endovascular procedure, immediate control digital subtraction angiography images were obtained to check the filling status of the aneurysm and the patency of the stents and intracranial arteries in the territory of the target artery. Hemostasis at the femoral puncture site was achieved using an arterial closure device (ExoSeal, Cordis, Miami Lakes, Florida; or Angio-Seal, St. Jude Medical, St. Paul, Minnesota). A control cranial CT examination was performed before the patient was transferred to the neurointensive care unit. Platelet aggregation testing was repeated before hospital discharge to confirm an inhibition ratio between $60 \%$ and $90 \%$. If needed, the antiplatelet drug dosage was adjusted according to the results of platelet aggregation testing. Dual antiplatelet therapy was continued for at least 6 months. Dual antiplatelet therapy was switched to aspirin thereafter.

\section{Angiographic Follow-Up}

Immediate postprocedural control DSA images were obtained at the end of the endovascular procedures to assess aneurysm occlusion according to the Raymond classification. ${ }^{19}$ The first angiographic follow-up was performed at 6-9 months after the endovascular procedure. The second angiographic follow-up was performed between 12 and 18 months. Considering the results of the second follow-up, the last follow-up DSA was performed at 24-48 months. Thereafter, patients were followed up with MR angiography. Follow-up angiograms were obtained to assess the aneurysm filling status and the development of in-stent stenosis or thrombosis. Progressive thrombosis on follow-up imaging was defined as an improvement in the Raymond class from sac or neck filling (Raymond class 3 or 2) to total occlusion (Raymond class 1). Recanalization was defined as a worsening of the Raymond class.

\section{Clinical Follow-Up}

A detailed neurologic examination was performed immediately after the endovascular procedure and at clinical follow-up to assess the development of any neurologic symptoms. Any clinical symptoms or signs that developed during the postoperative period were recorded. Patients' neurologic statuses were evaluated using the modified Rankin Scale during discharge and at clinical follow-up. Clinical follow-up was performed every 3 months in the first year, every 6 months in the second year, and annually thereafter.

Complications developing during the endovascular procedure or within 7 days following the procedure were defined as periprocedural. Clinical complications developing $>7$ days later were considered delayed complications.

\section{RESULTS}

\section{Patients, Demographics, and Aneurysms}

Forty patients (25 females and 15 males) with 46 intracranial aneurysms were identified. The mean age of the patients was $52.1 \pm$ 11.4 years (range, 16-65 years). Forty bifurcation aneurysms treated with the Y-stent-assisted coiling technique using LEO Baby stents were included in this study. Six aneurysms treated with other endovascular techniques were excluded from the statistical analyses. Thirty-eight of 40 aneurysms reported in this
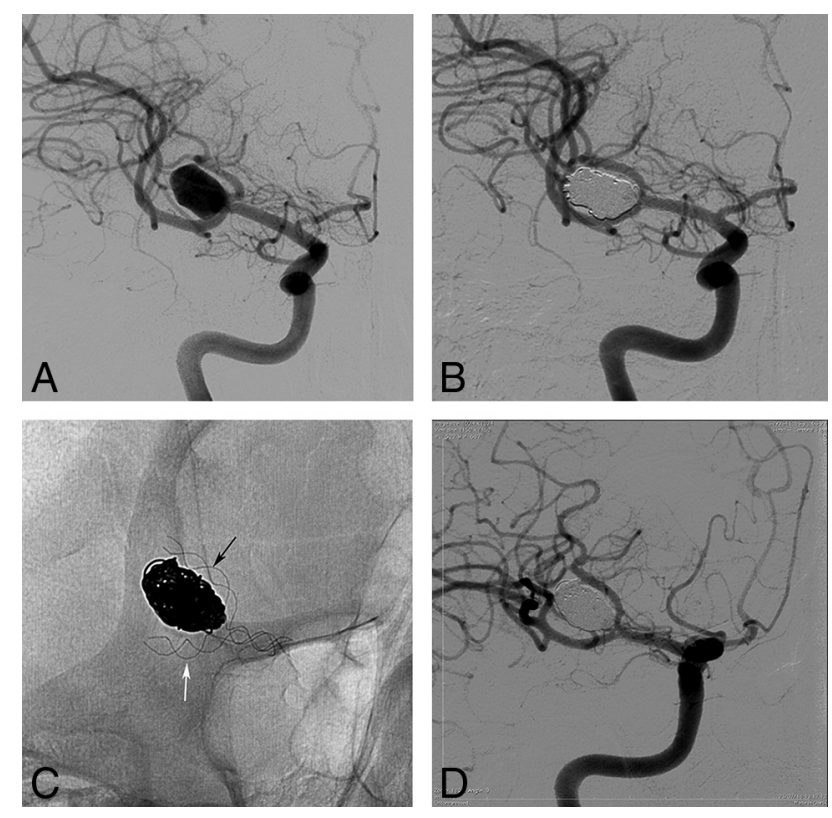

FIG 2. Procedural and follow-up angiographic images of a 58-yearold female patient with an unruptured MCA aneurysm. A, A preprocedural DSA image reveals a 12-mm, complex, wide-neck MCA bifurcation aneurysm. The neck of the aneurysm involves the origins of both daughter branches of the bifurcation. $B$, Immediate postprocedural DSA image shows that the aneurysm is completely occluded. C, Immediate postprocedural nonsubtracted angiogram obtained just before the contrast injection. The image shows the $\mathrm{Y}$-configuration of the LEO Baby stents overlapping in the M1 segment of the MCA and extending into the upper (black arrow) and lower (white arrow) trunks of the MCA.D, A 12-month follow-up DSA image demonstrates complete occlusion of the aneurysm.

study were unruptured. One patient had a wide-neck internal carotid artery bifurcation aneurysm that had ruptured 2 weeks before the endovascular treatment. Another patient had a recurrent anterior communicating artery aneurysm that had been previously coiled following its rupture. Thirty-seven of 40 aneurysms had not been treated previously. Two patients had recanalized anterior communicating artery aneurysms that had been previously treated by balloon-assisted coiling. Another patient with a middle cerebral artery aneurysm was referred to our hospital after a failed open surgery (clipping).

Twenty-two of 40 aneurysms were located in the MCA (55\%); 9 , in the anterior communicating artery $(22.5 \%) ; 7$, in the basilar bifurcation (17.5\%); and 2, in the ICA bifurcation (5\%) (Fig 2). The mean size of the aneurysms was $8.4 \pm 3.6 \mathrm{~mm}$ (range, 3-16 $\mathrm{mm}$ ). In 3 patients ( $7.5 \%)$, Y-stent-assisted coiling was performed as a bailout technique following coil protrusions developed during the single stent-assisted coiling procedures (Fig 3). Preoperative $\mathrm{mRS}$ scores were zero in all patients except 1 who had an mRS score of 2 because of a recent subarachnoid hemorrhage.

\section{Immediate Angiographic Results}

The deployment of 2 LEO Baby stents in a Y-configuration was achieved in all cases. A minor technical complication developed during stent deployment in 2 patients (5\%). In both patients, the first stents were not fully apposed to the vessel walls. An in-stent balloon angioplasty (Eclipse 2 L, GE Healthcare, Milwaukee, Wisconsin; Scepter XC, MicroVention) achieved full wall apposition 

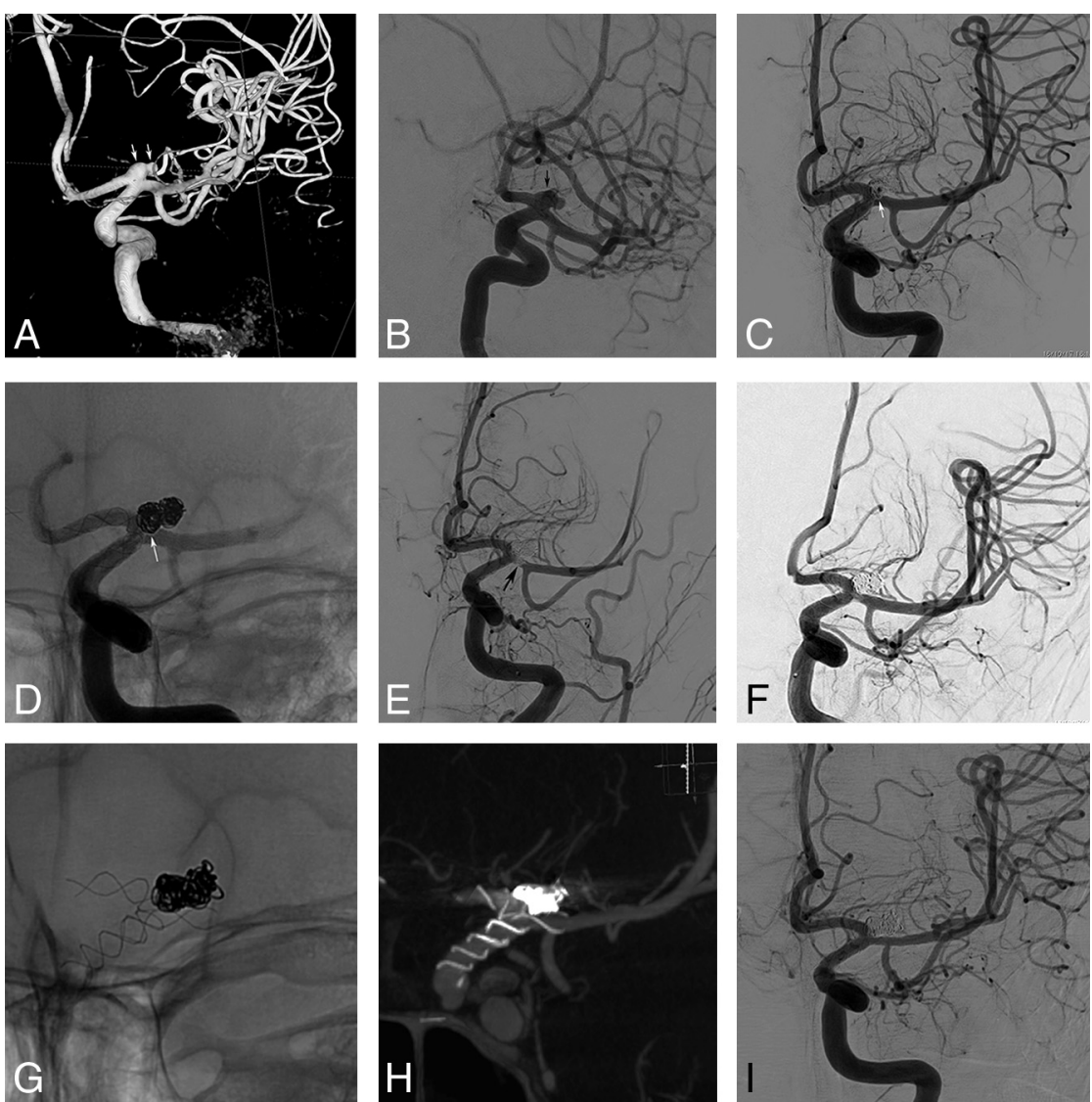

FIG 3. Procedural and follow-up angiograms of a 23-year-old male patient with unruptured bilateral ICA bifurcation aneurysms. Y-stent placement was performed as a bailout procedure after coil protrusion and consequent thrombus development following a single stent-assisted coiling treatment. $A$ and $B$, Preprocedural DSA and 3D reconstructed angiograms show a wideneck 6-mm aneurysm (arrows) located at the left ICA bifurcation. $C$ and $D$, Procedural control DSA and nonsubtracted angiograms show that the aneurysm has been coiled with the assistance of a single LEO Baby stent extending from the ICA to the left anterior cerebral artery. The coil mesh (arrows) protrudes into the M1 segment of the MCA. E, A procedural DSA image reveals the development of a thrombus (arrow) in the Ml segment of the MCA. F, DSA image obtained after a bailout deployment of a second LEO Baby stent into the MCA, creating a Y-configuration with the first stent. As shown in the image, the deployment of the second stent successfully treated the coil protrusion and restored the patency of the MCA. $G$ and $H$, Nonsubtracted angiography and an MIP reconstruction image of flat panel $C T$ show the $Y$-stent configuration with 2 LEO Baby stents. The images clearly show that there is no constriction of the second stent (deployed into the MCA) at the intersection point of the stents. I, A 12-month follow-up DSA image shows complete occlusion of the aneurysm and the patency of the stents.

in both cases. The immediate control DSA images revealed total aneurysm occlusion (Raymond class 1 ) in 29 patients $(72.5 \%)$, neck filling (Raymond class 2) in 10 aneurysms (25\%), and sac filling (Raymond class 3 ) in 1 aneurysm (2.5\%).

\section{Complications}

There was no mortality in this study. Periprocedural (6 patients, $15 \%)$ or delayed $(2.5 \%)$ complications developed in 7 patients $(17.5 \%)$. The complications resulted in neurologic symptoms in 5 patients $(12.5 \%)$ and a permanent neurologic deficit in 1 patient (2.5\%). In 2 patients, intraprocedural control DSA images revealed the development of in-stent thrombi. An intra-arterial bolus infusion of tirofiban (Aggrastat, $1.25 \mathrm{mg}$ diluted in $20 \mathrm{~mL}$ of saline) just proximal to the thrombi through the stent-delivery microcatheter caused complete resolution of thrombi in both cases. However, one of these patients experienced mild weakness in the contralateral upper extremity that completely regressed within 6 hours, and the mRS score of this patient was zero during discharge. One patient with a left MCA aneurysm developed right hemiplegia and dysphasia 4 hours after the completion of the endovascular procedure. Emergent DSA revealed total occlusion of the stent deployed into the upper MCA trunk. A bolus infusion of intra-arterial tirofiban through a microcatheter placed in the M1 segment of the MCA resulted in total recanalization. Although full recanalization was achieved, moderate hemiparesis and dysphasia persisted in this case. The patient's cranial MR imaging examination demonstrated cerebral infarction in the left parietal cortex, and his mRS score was 3 at the final clinical follow-up. In 1 patient with an ICA bifurcation aneurysm, Y-stent placement was performed as an emergent bailout technique to treat coil protrusion and consequent thrombus formation during a single stent-assisted coiling procedure. This patient developed dysphasia that completely resolved within 6 weeks. We observed minor hemorrhagic periprocedural complications in 2 patients (5\%) with MCA aneurysms. The immediate postembolization CT images revealed a thin layer of contrast extravasation confined to the ipsilateral Sylvian fissures in both cases. Neither patient developed any neurologic symptoms other than headache that lasted for 1-2 weeks. The mRS score of each patient was zero at discharge.

We observed a delayed thromboembolic complication $(2.5 \%)$ that remained asymptomatic. The first follow-up DSA of a patient with an ICA bifurcation aneurysm revealed the occlusion of the stent extending into the A1 segment of the anterior cerebral artery. The A2 segment and the cortical branches continued to fill from the anterior communicating artery, and the patient remained asymptomatic.

Preoperative platelet aggregation tests revealed an inadequate response to clopidogrel in 6 patients (15\%). The antiplatelet therapy was switched to prasugrel or ticagrelor, and no thromboembolic complication developed in these cases.

\section{Follow-Up}

Every patient had at least 1 follow-up angiographic examination. The mean duration of angiographic follow-up was 24.8 months (range, 6-48 months). The final follow-up angiographic examination revealed Raymond class 1 occlusion in 34 patients (85\%), Raymond class 2 occlusion in 5 patients (12.5\%), and Raymond class 3 in 1 patient (2.5\%). The follow-up angiography of a basilar 
tip aneurysm (2.5\%) with an immediate Raymond class 1 occlusion showed recanalization (Raymond class 3 ), after which it remained stable and did not require retreatment. Six of 11 aneurysms $(54.5 \%)$ with an immediate partial occlusion (Raymond class 2 or 3 ) showed progressive thrombosis resulting in an advancement in the Raymond class during follow-up.

The mean duration of clinical follow-up was 26.6 months (range, 6-48 months). The mRS score at the final clinical follow-up was zero in 38 of 40 patients. The mRS score of the patient with a preprocedural score of 2 did not change during the follow-up period. The patient who developed a periprocedural MCA infarction had an mRS score of 3 at the final clinical follow-up examination.

\section{DISCUSSION}

The Y-stent-assisted coiling technique involves the deployment of 2 proximally overlapping stents into the daughter branches of a bifurcation to reconstruct the wide neck of an aneurysm to prevent coil protrusion. The navigation of stent delivery catheters in the angulated daughter branches, the correct positing of stents, navigation of the second stent through the struts of the first deployed stent, and adequate expansion of the second stent at the intersection point are the relatively complicating technical parts of the Y-stent placement procedure. ${ }^{5,20}$ Laser-cut stents have been used in most previous studies on Y-stent placement. ${ }^{4-7,9}$ In the literature, the technical success rate of Y-stent-assisted coiling ranges between $86 \%$ and $100 \% .^{4-7,9,21}$ Recently, Bartolini et $\mathrm{al}^{5}$ reported the results of $\mathrm{X}$ - and $\mathrm{Y}$-stent-assisted coiling treatment of bifurcation aneurysms in 97 patients. These authors preferred to use open/open-cell or open/closed-cell laser-cut stent combinations for Y-stent placement. In their study, they reported the technical complications of excessively distal stent placement and dislocation of the first stents into the aneurysm sacs, resulting in incomplete treatment in $6.2 \%$ of the cases.

In a multicenter study reporting the results of Y-stent-assisted coiling using various open- and closed-cell stent combinations, technical complications related to stent deployment occurred in $6.7 \%$ of cases. ${ }^{6}$ In the current study, the rate of technical success was comparable with those reported in previous Y-stent-assisted coiling studies. Minor technical complications occurred in 2 patients (5\%). However, the complications did not cause treatment failure or permanent morbidity. In this study, we used LEO Baby stents, which could be delivered through low-profile microcatheters with luminal diameters of 0.0165 inches. Navigation in the acutely branched small-sized daughter vessels is easier and safer with low-profile microcatheters than with 0.21 -inch microcatheters. Furthermore, because the LEO Baby stents have a braided construction, they are resheathable or repositionable up to approximately $95 \%$ of their length, which is a major advantage over nonretrievable open-cell stents for precise stent placement. ${ }^{8} \mathrm{Be}-$ cause low-profile braided stents have smaller cell sizes than lasercut stents, there were unfounded concerns about the technical feasibility of Y-stent placement using low-profile braided stents. However, low-profile braided stents have a sliding-strut design that permits the movement of the struts over each other, causing the expansion of cells in the first stent to accommodate the second deployed stent in Y-stent placement. ${ }^{11,22}$
In a benchtop study, Makoyeva et $\mathrm{al}^{22}$ reported that Y-stent placement using self-expandable braided stents did not lead to metallic stenosis at the site of stent crossing. The compliant cell size of braided stents facilitates the passage of the microcatheter through the stent and reduces the constriction of the second stent between the struts of the first stent. ${ }^{23}$ In our cases, we applied a controlled axial force during the deployment of the second stent by pushing the delivery catheter together with the stent wire. This maneuver facilitates the expansion of the second stent during its deployment between the struts of the first stent. In this study, Y-stent construction was successfully achieved in every case with no major technical complications. The results of this study demonstrate that $Y$-stent placement using low-profile braided stents is technically feasible.

In this study, we observed the development of complications in $17.5 \%$ of cases. Most complications did not result in neurologic deficits, and permanent morbidity developed in only $2.5 \%$ of the patients. In a multicenter retrospective study, Fargen et $\mathrm{al}^{6}$ analyzed the clinical and angiographic outcomes of 45 aneurysms treated with a Y-stent-assisted coiling technique. Most included aneurysms were unruptured basilar tip aneurysms, and the investigators found a complication rate of $11.1 \%$. Bartolini et $\mathrm{al}^{5}$ reported a periprocedural complication rate of $19.6 \%$ and a permanent morbidity rate of $10 \%$ following Y- or X-stent-assisted coiling procedures. In another study, Spiotta et $\mathrm{al}^{21}$ assessed the medium-term results of Y-stent-assisted coiling procedures performed using first- and second-generation Neuroform stents (open cell; Stryker Neurovascular). The investigators observed an exceptionally high periprocedural complication rate of $31.6 \%$. Möhlenbruch et $\mathrm{al}^{13}$ reported the medium-term results in 8 patients who were treated with Y-stent-assisted coiling using a double LVIS Jr stent (MicroVention), which is a low-profile braided stent. The team observed a periprocedural ischemic complication in 1 of 8 patients $(12.5 \%)$ without any permanent consequences. The complication and morbidity rates of the current study are comparable with those of previous Y-stent-placement studies. The favorable clinical outcomes of the patients in the current study suggest that $\mathrm{Y}$-stent-assisted coiling using double low-profile braided stents is a relatively safe endovascular procedure for the treatment of complex bifurcation aneurysms.

In the literature, the immediate aneurysm occlusion rates following Y-stent-assisted coiling are variable. ${ }^{4-7,9,21}$ Spiotta et al reported that immediate complete occlusion was achieved in only $23.6 \%$ of the aneurysms treated with Y-stent-assisted coiling. ${ }^{21}$ In the study conducted by Fargen et al, ${ }^{6}$ the immediate total occlusion rate was $43 \%$. Bartolini et $\mathrm{al}^{5}$ reported an immediate complete occlusion rate of $46.7 \%$. In the literature, the immediate total occlusion rates following Y-stent-assisted coiling procedures are relatively low compared with the results of single-stent-assisted coiling studies. ${ }^{5,19,21}$ However, when interpreting these results, one should consider that aneurysms treated with the Ystent-assisted coiling technique are usually large and challenging with highly complex morphology. Furthermore, some surgeons might not force the coiling procedures to achieve immediate complete occlusion, relying instead on the flow-diverting capacity of the Y-stent placement configuration. ${ }^{9}$

In the current study, the rate of immediate total aneurysm 
occlusion was $72.5 \%$. These data show that complex bifurcation aneurysms could be effectively treated by coiling with the assistance of double low-profile stents in a Y-configuration. We observed immediate total or near-total occlusion (Raymond classes 1 and 2) in $97.5 \%$ of our cases, which is a noticeably high rate compared with the results of previous Y-stent-assisted coiling studies. ${ }^{4-8,21}$ The high scaffolding and flow-diversion capacity of the low-profile braided stent used in this study may have contributed to this relatively high immediate aneurysm occlusion rate. ${ }^{23,24}$ Furthermore, we did not rely on the flow-diversion capacity of the stents, and we continued the coiling procedure until complete occlusion was achieved or no further coils could be safely deployed.

The recurrence risk of aneurysms treated with stent-assisted coiling is significantly lower than that of aneurysms treated with primary coiling or balloon-remodeling techniques. ${ }^{25}$ Stents have some biologic and hemodynamic effects on the parent arteries that promote the progressive thrombosis of aneurysms and reduce the risk of recanalization. Implantation of stents causes a flow-diversion effect that decreases the hemodynamic stress on the aneurysm sac and facilitates thrombosis of aneurysms. ${ }^{26}$ Moreover, stent implantation induces endothelialization that progresses over the stent struts and leads to healing of the aneurysm neck. ${ }^{27}$ Kono and Tereda ${ }^{28}$ used a computational fluid dynamics model to investigate the hemodynamic effects of different stent-placement configurations. Those investigators found that the Y-stent-placement configuration caused the strongest reduction of flow velocity in aneurysms. Chalouhi et $\mathrm{al}^{29}$ reported that the recurrence and retreatment rates of basilar bifurcation aneurysms treated with Y-stent-assisted coiling were significantly lower than those of aneurysms coiled with the assistance of single stents. In support of these findings, we observed progressive thrombosis in $54.5 \%$ of the aneurysms with initial partial filling, and complete aneurysm occlusion was achieved in $85 \%$ of patients during the 24.8-month follow-up. Only 1 patient showed a recurrence, which did not require retreatment.

The current study has some limitations that should be acknowledged. This study was a nonrandomized retrospective study. Therefore, there was no control group of patients who underwent alternative endovascular treatments. Additionally, the effects of patient-selection bias cannot be excluded from the results.

\section{CONCLUSIONS}

Coiling with the assistance of double low-profile braided stents in a Y-configuration is a feasible endovascular technique. The longterm angiographic and clinical outcomes of this retrospective study demonstrate that Y-stent-assisted coiling using low-profile braided stents is an effective, relatively safe, and durable endovascular method for the treatment of wide-neck and complex bifurcation aneurysms.

\section{REFERENCES}

1. Akpek S, Arat A, Morsi H, et al. Self-expandable stent-assisted coiling of wide-necked intracranial aneurysms: a single-center experience. AJNR Am J Neuroradiol 2005;26:1223-31 Medline

2. Piotin M, Blanc R, Spelle L, et al. Stent-assisted coiling of intracranial aneurysms: clinical and angiographic results in 216 consecutive aneurysms. Stroke 2010;41:110-15 CrossRef Medline
3. Lopes DK, Johnson AK, Kellogg RG, et al. Long-term radiographic results of stent-assisted embolization of cerebral aneurysms. $\mathrm{Neu}$ rosurgery 2014;74:286-91 CrossRef Medline

4. Thorell WE, Chow MM, Woo HH, et al. Y-configured dual intracranial stent-assisted coil embolization for the treatment of widenecked basilar tip aneurysms. Neurosurgery 2005;56:1035-40; discussion 1035-40 Medline

5. Bartolini B, Blanc R, Pistocchi S, et al. "Y" and " $X$ " stent-assisted coiling of complex and wide-neck intracranial bifurcation aneurysms. AJNR Am J Neuroradiol 2014;35:2153-58 CrossRef Medline

6. Fargen KM, Mocco J, Neal D, et al. A multicenter study of stentassisted coiling of cerebral aneurysms with a Y configuration. $\mathrm{Neu}$ rosurgery 2013;73:466-72 CrossRef Medline

7. Akgul E, Aksungur E, Balli T, et al. Y-stent-assisted coil embolization of wide-neck intracranial aneurysms: a single center experience. Interv Neuroradiol 2011;17:36-48 CrossRef Medline

8. Aydin K, Sencer S, Barburoglu M, et al. Midterm results of T-stentassisted coiling of wide-necked and complex intracranial bifurcation aneurysms using low-profile stents. J Neurosurg 2017;127: 1288-96 CrossRef Medline

9. Chow MM, Woo HH, Masaryk TJ, et al. A novel endovascular treatment of a wide-necked basilar apex aneurysm by using a Y-configuration, double-stent technique. AJNR Am J Neuroradiol 2004;25: 509-12 Medline

10. Limbucci N, Renieri L, Nappini S, et al. Y-stent assisted coiling of bifurcation aneurysms with Enterprise stent: long-term follow-up. J Neurointerv Surg 2016;8:158-62 CrossRef Medline

11. Akmangit I, Aydin K, Sencer S, et al. Dual stenting using low-profile LEO baby stents for the endovascular management of challenging intracranial aneurysms. AJNR Am J Neuroradiol 2015;36:323-29 CrossRef Medline

12. Behme D, Weber A, Kowoll A, et al. Low-profile visualized intraluminal support device (LVIS Jr) as a novel tool in the treatment of wide-necked intracranial aneurysms: initial experience in 32 cases. J Neurointerv Surg 2015;7:281-85 CrossRef Medline

13. Möhlenbruch M, Herweh C, Behrens L, et al. The LVIS Jr. microstent to assist coil embolization of wide-neck intracranial aneurysms: clinical study to assess safety and efficacy. Neuroradiology 2014;56: 389-95 CrossRef Medline

14. Conrad MD, Brasiliense LB, Richie AN, et al. Y stenting assisted coiling using a new low profile visible intraluminal support device for wide necked basilar tip aneurysms: a technical report. J Neurointerv Surg 2014;6:296-300 CrossRef Medline

15. Samaniego EA, Mendez AA, Nguyen TN, et al. LVIS Jr device for Y-stent-assisted coil embolization of wide-neck intracranial aneurysms: a multicenter experience. Interv Neurol 2018;7:271-83 CrossRef Medline

16. Shankar JJS, Quateen A, Weill A, et al. Canadian registry of LVIS Jr for Treatment of Intracranial Aneurysms (CaRLA). J Neurointerv Surg 2017;9:849-53 CrossRef Medline

17. Iosif C, Piotin M, Saleme S, et al. Safety and effectiveness of the low profile visualized intraluminal support (LVIS and LVIS Jr) devices in the endovascular treatment of intracranial aneurysms: results of the TRAIL multicenter observational study. J Neurointerv Surg 2018; 10:675-81 CrossRef Medline

18. Aydin K, Arat A, Sencer S, et al. Stent-assisted coiling of wide-neck intracranial aneurysms using low-profile LEO Baby stents: initial and midterm results. AJNR Am J Neuroradiol 2015;36:1934-41 CrossRef Medline

19. Raymond J, Roy D. Safety and efficacy of endovascular treatment of acutely ruptured aneurysms. Neurosurgery 1997;41:1235-45; discussion 1245-46 CrossRef Medline

20. Spiotta AM, Lena J, Chaudry MI, et al. Y-stenting for bifurcation aneurysm coil embolization: what is the risk? Stroke Res Treat 2014; 2014:762389 CrossRef Medline

21. Spiotta AM, Gupta R, Fiorella D, et al. Mid-term results of endovascular coiling of wide-necked aneurysms using double stents 
in a Y configuration. Neurosurgery 2011;69:421-29 CrossRef Medline

22. Makoyeva A, Darsaut TE, Salazkin I, et al. Y-crossing of braided stents with stents and flow diverters does not cause significant stenosis in bench-top studies. Interv Neuroradiol 2013;19:455-60 CrossRef Medline

23. Aydin K, Barburoglu M, Sencer S, et al. Flow diversion with lowprofile braided stents for the treatment of very small or uncoilable intracranial aneurysms at or distal to the circle of Willis. AJNR Am J Neuroradiol 2017;38:2131-37 CrossRef Medline

24. Cho SH, Jo WI, Jo YE, et al. Bench-top comparison of physical properties of 4 commercially-available self-expanding intracranial stents. Neurointervention 2017;12:31-39 CrossRef Medline

25. Chalouhi N, Starke RM, Koltz MT, et al. Stent-assisted coiling versus balloon remodeling of wide-neck aneurysms: comparison of angiographic outcomes. AJNR Am J Neuroradiol 2013;34: 1987-92 CrossRef Medline

26. Cantón G, Levy DI, Lasheras JC. Hemodynamic changes due to stent placement in bifurcating intracranial aneurysms. J Neurosurg 2005; 103:146-55 CrossRef Medline

27. Kadirvel R, Ding YH, Dai D, et al. Cellular mechanisms of aneurysm occlusion after treatment with a flow diverter. Radiology 2014;270: 394-99 CrossRef Medline

28. Kono K, Terada T. Hemodynamics of $\mathbf{8}$ different configurations of stenting for bifurcation aneurysms. AJNR Am J Neuroradiol 2013; 34:1980-86 CrossRef Medline

29. Chalouhi N, Jabbour P, Gonzalez LF, et al. Safety and efficacy of endovascular treatment of basilar tip aneurysms by coiling with and without stent assistance: a review of 235 cases. Neurosurgery 2012;71:785-94 CrossRef Medline 